Eleazar Huerta

\title{
La prosa de Ortega
}

\section{UNA PROSA DE ESTILO CONSCIENTE}

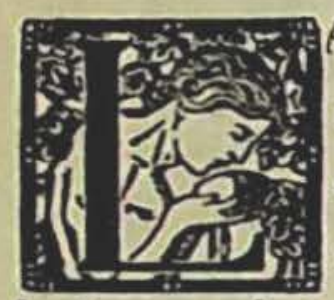

A prosa de Ortega se impone al lector de modo tan inmediato, particularmente por su variedad de recursos, que invita a gozarla pero desanima el intento de análisis. ¿Por dónde empezaríamos? Inventariar el vocabulario, catalogar las figuras retóricas, usar - en suma- métodos estadísticos, sería enfadoso y de poco fruto. Hace años que los métodos estadísticos están en baja, porque han resultado poco eficaces hasta en el estudio de la poesía lírica, la literatura más concentrada, la más fácil de caracterizar. Usarlos para esclarecer la prosa de un filósofo sería, por eso, ganas de perder el tiempo. Resultaría preferible seleccionar los rasgos dominantes y tratar de sistematizarlos; no todo el vocabulario sino el preferido, no cualquier neologismo sino el típicamente orteguiano, y seguir así en todas las etapas del análisis. Mas ¿con qué criterio haríamos la selección? ¿Dejándonos llevar por nuestra intuición de lectores? Entonces nos perderíamos en el estilo de Ortega como en una selva. La gran variedad a que antes me referí nos mostraría tantas formas, además tan diferentes y que todas llaman en algún momento la atención, que no habría modo de jerarquizarlas porque de ninguna querríamos prescindir.

Habrá que seguir otras rutas, por tanto. 
No deja de ser cierto que el estilo de Ortega produce una im presión de conjunto que es siempre la misma: une señorío y gracia, exquisitez minoritaria y salero popular. Pero el dar con està constante no sirve, sin más. Se trata de un efecto del estilo, nó de sù causa generatriz. No se pueden sacar consecuencias de la ultraconsecuencia.

Por fortuna, el propio Ortega viene en nuestra ayuda. El, enamorado de poner problemas en claro, dijo lo bastante sobre sí mismo para darnos la interpretación auténtica de su estilo. Ha escrito de cierta manera - nos cuenta- porque dedicó su vida a cierto menester - la filosofía- dentro de la circunstancia española. En el prólogo a la primera edición de sus Obras completas aparecen las palabras siguientes:

"Hay que hacer nuestro quehacer. El perfil de éste surge al enfrentar la vocación de cada cual con la circunstancia. Nuestra vocación oprime la circunstancia, como ensayando realizarse en ella. Pero ésta responde poniendo condiciones a la vocación. Se trata, pues, de un dinamismo y lucha permanente entre el contorno y nuestro yo necesario. Mi vocación era el pensamiento, el afán de claridad sobre las cosas. Acaso este fervor congénito me hizo ver muy pronto que uno de los rasgos característicos de mi circunstancia española era la deficiencia de eso mismo que yo tcnía que ser por íntima necesidad. $Y$ desde luego se fundieron en mi la inclinación personal hacia el ejercicio pensativo y la convicción de que era cllo, además, un servicio a mi país. Por eso toda mi obra y toda mi vida han sido servicio de España. Y esto es una verdad inconmovible, aunque objetivamente resultase que yo no había servido de nada...

"Pero esta propaganda de entusiasmo por la luz mental - EL LUMEN NATURALE- había que hacerla en España según su circunstancia impusiera. En nuestro país, ni la cátedra ni el libro tenían oficiencia social. Nucstro pueblo no admite lo distanciado y solemne. Reina en él puramente lo cotidiano y vulgar. Las formas del aristocratismo "aparte" han sido siempre estériles en esta península. Quien quiera crear algo -y toda creación es aristocracia - tiene que acertar 
a ser aristócrata en la plazuela. He aquí por qué, dócil a la circunstancia, he hecho que mi obra brote en la plazuela intelectual que es el periódico. No es necesario decir que se me ha censurado constantemente por ello. Pero algún acierto debia haber en tal resolución cuando de esos articulos de periódico han hecho libros formales las imprentas extranjeras".

Según el texto transcrito, la fórmula general del vivir humano - "Yo soy yo y mi circunstancia"- sería para el propio Ortega, individualmente, esta otra más concreta: "Yo soy un filósofo obligado por la circunstancia española a filosofar al nivel del pueblo".

Pero aquella fórmula general del vivir humano, como hice ver en otra ocasión (en el homenaje a Ortega, de la Facultad de Filosofía y Educación y la Sociedad de Filosofía, de 18 de noviembre pasado) lleva implícitos para Ortega los siguientes supuestos:

1. Vivir no es algo pasivo, ni consiste ante todo en razonar, pues el hombre no es definible como homo sapiens. Vivir es decidir en cada momento qué cosa hacer, en vista de un proyecto vital. Luego vivir es drama, algo muy parecido a representar en serio el personaje fantástico que queremos ser. El yo es dramático más que racional.

2. La circunstancia es lo dado, lo vigente, tanto físico como social. Y las vigencias sociales incluyen, en primer término, las idiomáticas. Pensamos en una cierta lengua, que constituye una prefilosofía, todo un sistema de modos de pensar. Mas esto tiene un grave riesgo; los modos de pensar idiomáticos, por sernos dados y no constituir problemas para nosotros, se subentienden. No hace falta decirlo todo - tampoco sería posible- porque quien nos oye comparte la misma prefilosofía y nos entiende. Pero jojo! este hecho se torna grave si el hábito reduce a inconscientes los presupuestos del idioma. Entonces puede ocurrir que vicien el rigor de nuestro pensamiento, que no nos entendamos a nosotros mismos. Por otra parte, en cuanto hemos de entender a un hombre de otra época o de otro país, hay que estar muy alerta, pues las circunstancias y el sentido de las palabras, todo cambia. Así que para comprender bien al extran- 
jero y al antiguo hay que entenderles mejor que ellos se entendían: haciendo conscientes los presupuestos que eran inconscientes, por obvios, para ellos.

Recordadas todas estas ideas de Ortega, podemos volver a analizar aquella impresión general que deja su prosa - señorío y gracia- y preguntarnos si estamos ante una síntesis a compromiso del afán por ver claro del filósofo - de donde brota el señorío- y del propósito de hacerse asequible al público español, al "vulgo de la plazuela”, de donde, a su vez, mana la gracia.

También podemos declararnos insatisfechos ante una hipótesis tan simple. ¿Acaso las formas graciosas tomadas del habla popular no constituirán, más bien, parte del empeño por entenderse a sí mismo, desvelo que Ortega hace de sus presupuestos idiomáticos hispanos? Bien pudiera ser, en todo o en parte. Mas entonces, ¿dónde estarían las concesiones hechas por nuestro filósofo a esos lectores de periódicos? ¿No dice palmariamente que su vida entera ha estado al servicio de ellos, les haya o no resultado útil?

Algo hemos aclarado, pues, pero todavía poco. Sabemos que Ortega se ha hecho problema del modo de escribir, que su estilo es consciente. El nos lo ha dicho. Mas no está claro cómo se conjugan en su prosa el afán de expresarse con claridad y por completo con el de comunicar inequívocamente lo pensado.

\section{LOS GRADOS DE LO CONSCIENTE}

En un sentido amplio, todo estilo es consciente. El artista busca forma para expresarse de un modo entre lúcido y sonambúlico, pero corrige conforme va haciendo, se detiene, medita, apoya la nueva frase en la anterior para continuar su alcance e irlo perfilando. Si el primer hallazgo puede a veces ser una casualidad, los actos posteriores de mantenerlo en el texto, combinarlo con otros rasgos idiomáticos concordes y lograr un sistema de formas -o sea, el estiloson cosa deliberada, cultivada, de que el creador se da cuenta. Son actividad consciente. 
Pero hay otros sentidos más precisos del estilo. Podemos mirar a éste: $10^{\circ}$ Como el empleo de formas reductibles a una teoría, a una serie de principios generales, de los cuales el estilo es aplicación. 2. Como dicho acuerdo entre el hacer y la teoría, pero añadiendo que el autor ha llegado a formular expresamente la teoría que aplica.

Ortega, en Papeles sobre Velázquez y Goya, se ha referido a la consciencia estilística del pintor, en primer término. Allí exime al artista plástico de tener que formular principios, tarea que es obligada, en cambio, para el crítico:

"Tenemos la obligación de resolvernos a transponer en conceptos las acciones $y$ omisiones del pintor".

Lo que espera del pintor es que sea prudente y no teorice, pues si lo hace se equivocará, por mucho que sea su talento:

"Ser pintor es resolverse a la mudez. Cuando un pintor se pone a "decir", a teorizar sobre su arte, lo que nos comunica no suele tener apenas que ver con lo que él mismo hacía. Ejemplo, el Trattato della Pittura, de Leonardo de Vinci".

Ahora bien, continúa, el caso de la literatura no es el mismo. La obra literaria, que tiene de común con el cuadro o la sinfonía el ser un sistema de signos, es de un sentido declarado, patente, en vez de enigmático. Claro está que esa comunicación palmaria de la lengua posee sus propias limitaciones:

"La principal consiste en que sólo puede decir cosas muy generales. Ya el simple matiz determinado de un color es incfable".

En seguida -y Ortega insiste una vez más en cosas que ya sabemos- el decir se apoya en los presupuestos idiomáticos de la comunidad: decimos algo porque callamos y subentendemos mucho; lo subentendido es en parte consciente y en parte inconsciente; hay que tener en cuenta estas realidades cuando nos dirigimos a un público distinto al habitual o tratamos de entender a uno antiguo, etc.

Al escribir habrá que navegar por estas sirtes de manera que remediemos los dos escollos principales, que Ortega dice haber formulado en otra obra suya, compuesta de veras o no, acaso tan real como la segunda parte de La Galatea. Lo cierto es que afirma: 
"En un estudio titulado Principios de una Nueva Filología que espero dar pronto a la estampa, formulo, entre otras, dos leyes de apariencia antagónica, que se cumplén en toda enunciación. Una suena así: "Todo decir es deficiente" - esto es, nunca logramos decir plenamente lo que nos proponemos decir. La otra ley, de aspecto diverso, declara: "Todo decir es exuberante" -esto es, que nuestro decir mANIFIESTA siempre muchas más cosas de las que nos proponemos $e$ incluso no pocas que qucremos silenciar. El cariz contradictorio de ambas proposiciones desaparece con sólo advertir que defecto $y$ temasia van referidos formalmente, como a un nivel, al decir. Ahora bien, decir es siempre un QUERER decir TAL COSA DETERMINADA. Esta cosa determinada es la que jamás logramos decir con plena suficiencia. Sicmpre habrá una cierta inadecuación entre lo que en la mente teníamos $y$ lo que efectivamente decimosn.

Aún debemos añadir algo que Ortega atribuye concretamente a la literatura filosófica. Para él, que huye de la beatería filosófica - como de la artística o la política -, no es la filosofía un enrarecido y esquemático análisis de unos pocos, altos y solemnes temas: es más bien un método para pensar con rigor y ver claramente cómo son las cosas, las grandes y monumentales o las modestas.

"Se trata, pues, de una trayectoria en que cada paso nos obliga a dar el siguiente con dialéctica necesidad. Esta dialéctica no es de conceptos sino real, no es del Logos sino de la cosa misma. Es la dialéctica del hilo al tirar del cual sacamos el ovillo".

Merced a esta dialéctica de la cosa, Ortega puede arrancar del hecho más trivial, pero de causa en causa y de una aclaración en otra, llega siempre lejos, hasta las verdades del ovillo, que son las del universo entero, las filosóficas. Por lo mismo, gusta de abordar problemas fundamentales desde posturas previas, obvias, con humildad inicial que nos garantice en seguida el buen planteamiento de la cuestión. Ahora bien, este método ha de influir - no puede menos que ser así- en el plano de la composición. Por encima de la frase, Ortega tendrá un estilo demostrativo peculiar, el impuesto por esa dialéctica de la cosa, que es el método de la razón vital. Mas el mé- 
todo cala en la formulación de cada frase, ahonda en aquello de la "deficiencia" y la "exuberancia" expresivas. El idioma nos engaña constantemente, porque creemos haber desentrañado algo en cuanto le hemos puesto nombre. Ortega llama a este vicio de la razón lógica la "falacia del atributo":

"Aplicamos a un sujeto un atributo, pero éste se nos vuelve león y se traga al sujeto sin que quede de él ni la raspa. Se trata de una enfermedad constante que padece el intelecto. Yo intento aquí reobrar radicalmente contra ese morbo y siguiendo, como siempre, dócil a mi maestro Perogrullo, invito a reparar que si es cierto decir de un hombre que es pintor, es mucho más cierto afirmar que ese pintor es un hombre, y que lo es, no sólo aparte de ser pintor sino en tanto que pintor, pues pintar no es, en absoluto, otra cosa que una manera de ser hombre".

La falacia del atributo es, pues, una ilusión idiomática que vicia la verdad de una frase. La siguiente, que se apoya en tal error parcial será más errónea todavía, y así sucesivamente. Mas si el atributo fucra deliberadamente ocasional y metafórico, no caeríamos en el error de tomarlo neciamente por verdad total que puede afirmarse del sujeto. El decir poético, si hace consciente la índole siempre metafórica del idioma, resulta una garantía para la dialéctica de la cosa.

Con el resumen anterior, aunque modesto, creo yo que tencmos ya una base para entender el estilo de Ortega. El lector habrá observado que desde un principio he venido manejando unas mismas ideas de nuestro filósofo - relaciones entre lengua y pensamiento, literatura y vida-, mas primero en un sentido y después en el contrario. En efecto, si nos orientamos hacia la filosofía, meditar sobre dichas relaciones y aclararlas proporciona a Ortega unos temas filosóficos y le sugiere un método, tanto de investigación como de exposición: su dialéctica. Pero si miramos del otro lado, hacia la literatura, todo este bagaje de ideas y de métodos hace de él un ensayista en vez de un expositor sistemático conforme a la vieja lógica. Y tal ensayista empleará un estilo cuya belleza no es adorno ni disfraz 
de la verdad sino garantía de la misma. Como la verdad es supralógica, ha de ser captada y expuesta poéticamente.

\section{ALGUNOS RASGOS DEL ESTILO DE ORTEGA}

Con los criterios de interpretación que hemos visto, pongámonos ahora a filiar unos cuantos rasgos del estilo orteguiano.

Siempre los neologismos o las palabras poco usuales clevadas al nivel de preferidas son algo típico de un estilo. En el de Ortega no falta dicho rasgo. Veamos algunas de estas palabras, como ejemplo, porque inventariarlas ahora sería aburridísimo. El maestro dice "jeroglifo" en vez de jeroglífico, "feminidad" y no femineidad, "rigoroso" por riguroso, "nudo", "sólito", en lugar de desnudo y de frecuente, etc. Son casos, todos, en que Ortega se revuelve contra el diccionario. Pero no lo hace por capricho y desordenadamente. Lo que hay es que la etimología y el uso consagrado, que son dos leyes para la gramática tradicional, valen menos para él que la gran verdad lingüística de mirar el castellano como un sistema de signos. La terminación "ico" es, en castellano, un morfema para crear adjetivos, por derivación: "prolífico", de prole, "científico", de ciencia, "beatífico", de beato; luego "jeroglífico" es un adjetivo ("signos jeroglíficos", "escritura jeroglífica") cuyo sustantivo de origen bien pudiera ser "jeroglifo". También "feminidad", a tenor de nuestro sistema de derivación, es un abstracto análogo a "masculinidad", "oportunidad", "probidad"; en cambio, "femineidad" constituye una excepción inadmisible, máxime si tenemos en cuenta que "feminoide" significa lo falsamente femenino, lo que parece femenino pero no lo es. A su turno, "rigoroso" deriva del castellano "rigor" y no de una lengua extraña, la latina, cual "riguroso". Y si existe el compuesto "insólito", es de razón que "sólito" pertenezca al acervo del idioma, lo mismo que "nudo", voz primitiva con relación a "desnudo".

Es indudable: Ortega prueba en casos como los citados y otros de igual carácter su señorío consciente de nuestra lengua, valoriza 
el sistema sincrónico de la misma sobre el uso, que es tradición descuidada, y se resiste a mezclar las categorías gramaticales.

En la formación de palabras compuestas y uso de sintagmas con sabor popular hallamos otro rasgo estilístico ya claro, con las iluminaciones anteriores. Bien venido sea lo popular siempre que desvele la prefilosofía encerrada en formas como "estar en sí", "estar fuera de si", o la compuesta "ensimismamiento", y lo mismo "alteración" - las dos últimas forman el título de un libro del maestro-; y no digamos si se llega a aciertos cual llamar al loco "enajenado", y a distinguir lo individualmente "sabido" de lo "consabido" social. Todo esto pertenece al tesoro de las vigencias idiomáticas cuya consciencia conviene reavivar. De ordinario, se nos olvida su hondura; "por sabido se calla", según otra locución llena de sentido que él a menudo cita. ¡Pues a evitarlo!

En un segundo caso prefiere voces populares a sinónimos de nivel más aséptico y erudito: cuando el "plebeyismo" está cargado de vivencias próximas. Dirá "bronca en la física" - titula así un artículo- en vez de discusión o debate para subrayar cuánto tiene de escándalo el que la ciencia se aparte sin remedio de la observación. También preferirá afirmar que la poesía y la pintura son "faenas de comunicación" a que son tareas o funciones. Es que "faena", que para el público español tiene dos vivencias inmediatas, la agrícola y la taurina, funde con el significado de trabajo o tarea la de productividad germinativa y la de hazaña. Pintar es "faena" porque produce maravillosamente una maravilla.

En metáforas cual "punzar un problema" - como si fuera una pleuritis-, o bien agarrar y aislar "con las pinzas de la atención" este y el otro asunto -igual que hace el entomólogo con el insectovemos el afán por huir de la frase abstracta, con su riesgo del atributo falaz y, a la par, del decir deficiente. Por otra parte, incorporar estos giros a la lengua viene a ponerla "al nivel de los tiempos", inyectándole el saber científico ya divulgado, mas sin que lo metafórico se haga inconsciente y se gramaticalice. Ya sabemos cuán de 
mala gana se acepta en la filosofía orteguiana continuar en el campo metafórico que tenían los arios y creer que hablamos "en serio".

Con las duplicaciones y triplicaciones persigue también Ortega deshacer el prestigio de la palabra única, para que no se trague al sujeto, reduciéndolo en significación. Pero, al lado, estas cnumeraciones, con sus paralelismos y contrastes, hacen visible el juego del material sonoro: rimas, aliteraciones, similicadencias, paronomasias, que trascienden normalmente a la ironía y nos alertan. Así que Ortega, al emplear estas viejas figuras retóricas, no está simplemente ahuecando la voz. Por descontado que está saboreando el idioma. Todo estilista posec la sensualidad idiomática. Pero no encubre tras la sonoridad la pobreza de ideas -estigma tradicional de la oratoria- sino que hace todo lo contrario. En verdad, singulariza, logra salir de la mención "palmaria" pero "general" para captar esa matiz "inefable" que tienen las cosas y pierden con el uso descuidado las palabras. He aquí un ejemplo: "Lo que pasa es que los oficios son propiamente figurines o figurones sociales, con carácter, como todo lo social, genérico, típico y tópico". Ciertamente, podríamos hallar otros ejemplos a montones, mas lo creo inútil, tras ejemplar tan concluyente.

El ejemplo metafórico, uno de los rasgos en que culmina el estilo de Ortega, funde la necesidad expresiva propia, que se satisface al explayarse, con la consciencia de escribir para ụn público. En una misma página de los Papeles sobre Velázquez y Goya hay dos muy representativos: "El artista necesita de las presiones que una vida difícil ejerce sobre él, como el limón necesita ser estrujado para dar su zumo". Esto - sigue diciendo el autor- le faltó a Velázquez, quien al ser nombrado pintor del rey siendo muy joven, ya lo tuvo conseguido todo. "La consecuencia es que quedó vacío de tensión vital, como una pila eléctrica que se descarga de su potencia”. Lo que se compara no son simples conceptos - vida con limón, abulia cón pila descargada- sino dos procesos, dos complejos acaeceres en ejecución. Suele compensarse lo trivial del ejemplo -que da fuerza a la demostración- con el primor de la sonoridad. 
En sentido contrario al ejemplo metafórico, la alusión cultural ilumina un problema al divisar su paralelo con otro problema lejano y tender entre ambos un puente audaz. He aquí una alusión a Kant, revolucionario en el mundo del pensamiento, lanzada desde los dominios del arte. Velázquez ha dejado de dar relieve escultórico a sus figuras, las ha convertido en puros fantasmas ópticos. Pues bien: "Las Meninas vienen a ser algo así como la crítica de la pura retina”. $\mathrm{Na-}$ turalmente, en su contexto, la paráfrasis es mucho más valiosa que en la cita aislada. Hace notar dos hechos paralelos. Y trasciende a sugerir que - en la evolución histórica de la filosofía y de la pintura- estas dos conquistas son casos de un mismo principio depurativo.

\section{EL GARBO COMO GRACIA DEL RITMO ORTEGUIANO}

En definitiva, como ocurre con cualquier estilo, importa más el hecho de cómo se organizan y funcionan entre sí los distintos rasgos que la índole singular de cada uno. En el caso de Ortega, según ya sabemos, cada una de las frases, con su plenitud de valores, es miembro de una parrafada en donde se utiliza la dialéctica de la cosa para llegar a una verdad vital. El párrafo entero, como unidad de composición, es, pues, un juicio de índole supralógica, de notoria semejanza externa con el párrafo poético. Está orientado siempre hacia la busca y revelación de la verdad objetiva. En él se filosofa. Mas el despliegue que a menudo hace del punto de vista del autor, situado en una circunstancia histórica, es innegable. Esto no es subjetivismo lírico, explica Ortega, sino perspectivismo (Introducción a El Espectador, I; El sentido histórico de la teoría de Einstein, etc.). Toda verdad humana sobre el mundo es perspectiva, está lograda desde el aquí, el ahora y la experiencia de cierto yo. Ahora bien, si esto es así hacia la vertiente filosófica, no lo es menos, del lado literario, que ciertos trozos de Ortega, al aislarlos del contexto, merecen ser reputados de poéticos, pura y simplemente. El caso es el mismo que cuando en un drama aislamos un fragmento lírico, o en un tratado de física la historia de un descubrimiento. 
Hay, por todo eso, párrafos singularmente bellos en Ortega, por las mismas virtudes aparentes que en la novela y la historia. El hecho no puede extrañarnos. Por algo el ensayo, mirado como poesía de las ideas, har ido ganando día a día un puesto mejor en la literatura. Pero el párrafo de Ortega en general posec otro mérito: una gracia rítmica muy suya, que se capta de inmediato. Ha llegado el momento de procurar entenderla, de buscar sus raíces. Y de aclarar, por fin, cómo paladeamos la pareja "señorío-gracia” en tal estrato. Empezaré por copiar un texto de Ortega, una parte de su Brindis en el P.E.N. Club de Madrid:

"Recuerdo en este momento una de las escenas más castizas que he tenido la suerte de presenciar en los últimos años. Fué hace cinco o seis. Recordaréis que entonces cayó sobre toda Europa un invierno crudísimo. En Madrid habia feroces nevadas. Yo estaba una noche cenando en el Café de Levante. Había ido allí, como hago alguna vez, de escapada, para, recogido sobre mi mismo, abrirme los poros a la casticidad que pasa. Habia junto a mi mesa otra donde se reunía una tertulia de la pequeña clase media madrileña. Una tertulia de las que merecen el título de hipertertulias porque cra tertulia de después de cenar, de hombres que después de haber estado dos o tres veces de tertulia durante el día vuelven otra vez a ella, pase lo que pase. Brindo la imagen al señor Arniches, que diviso allá, sentado. Ya veréis por qué. Se hallaba bastante nutrida la tertulia cuando surge un nuevo elemento. Un hombre de magnífico porte, aventajado de talla, aspecto de gran chulo, como ya quedan pocos. Sombrero blando $y$ ancho, a lo LAgartijo; capa de estupendos embozos, que traía todos salpicados de copos de nieve; bastón con el puño de asta de cicrvo. Al llegar junto a sus contertulios, se desembozó con un espléndido gesto y les saludó diciendo:

"-Scñores, ¡buenas noches... teóricamente!

"Nunca he visto más enérgicamente vivida la idea que nuestro pueblo se hace de la teoría. Teoría, para él, es precisamente lo que no tiene nada que ver con la realidad, lo que jamás coincide con ella".

Sólo por la reflexión final, esta graciosa estampa de costumbres, 
que Ortega brinda al sainetero Arniches, penetra en el ámbito filosófico. Se nos confirma lo dicho sobre el valor narrativo de un trozo, compatible con que quede englobado en el clima del ensayo, más amplio. Pero vengamos a lo que ahora importa.

El filósofo nos hace confidencias. A veces, de escapada, busca el café u otro ambiente popular, para empaparse de casticismo. Y esta vez tuvo suerte: vió a un gran chulo, como quedan pocos, y pudo admirar el espléndido gesto con que dijo algo gracioso pero absurdo. Hay, pues, una gracia de movimientos que el pueblo español posee y que su filósofo gusta de ir a observar. Hay hasta un modo gracioso de decir disparates. Pero con ello llegamos a los límites de lo tolerable. Tendría poca gracia que lo gracioso se erigiera en base bastante para la vida. Mas así ha ocurrido y ocurre en la historia de España. De ahí la retórica, el esperpento, lo descomunal. En el siglo XVIII, la aristocracia española llegó a enamorarse de las danzas, los trajes, los cantares y diversiones de la plebe. Había dejado de ser aristocracia verdadera, creadora, y copiaba. Algo más grave: en la centuria anterior, porque don Rodrigo Calderón subió airosamente al merecido cadalso - fué político, ladrón y corrompido- el pueblo español entero pasó a admirarlo fanáticamente. Sus ropas y hasta el cuchillo con que fué degollado se convirtieron en reliquias, que guardaron monjas y coleccionistas. Son cosas éstas sobre las cuales ha meditado Ortega. Lo vemos en sus ya citados Papeles. Así que, conscientemente, hace una clara divisoria a lo largo de todos sus escritos. De un lado, admira la prefilosofía de ciertas palabras y giros populares, así como el plebeyismo idiomático justificado por ricas vivencias. Añade a esto la gracia en los movimientos. Y nada más. De ahí no pasa. Lamenta en toda ocasión que en España no haya habido verdadera aristocracia, que hasta la colonización de América fuese empresa popular. Como digo, esa postura de Ortega es constante, aunque en ciertas obras, como su España invertebrada, se haga más visible, por la insistencia. Otros españoles, no solamente Ortega, han señalado esta justificación de lo gracioso que efectúa la sociedad española. En ninguno, sin embargo, me parece hallar un 
límite tan bien escogido. Galdós, que lamentaba el desbarajuste político y el atraso españoles - la oratoria estéril, los curas con trabuco-, se rindió sin condiciones ante el plebeyismo idiomático y lo admitió por completo. Su estilo de narrador no es más que el de un castizo costumbrista. Baroja, a quien indignaba que una quintilla graciosa bastara para obtener un empleo fiscal, cayó en el disparate de ver retórica inmunda en toda la tradición del idioma. Unamuno, tan parecido al Greco en sus técnicas manieristas, se dedicó a descoyuntar y destripar vocablos y osciló, en la teoría, desde renegar de lo castizo hasta exaltar lo hispánico frente a lo europeo. No puede negarse: contrastado así, Ortega aparece equilibrado y sin contradicciones.

La gracia española en los movimientos, nos precisạ Ortega, tiene un nombre propio: es el "garbo". García Lorca nos lo recuerda, al decir del gitano de sus romances: "anda despacio y garboso". En verdad, la gracia española apresurada, de ratón o de pajarillo, la que han recogido los hermanos Alvarez Quintero, no es la definitiva, no es el garbo. El garbo se manifiesta en el buen porte y en el ademán sosegado, seguro de sí mismo. Está en ese gran chulo de aventajada estatura que se desemboza lenta, espléndidamente, mientras saluda a sus amigos. Un gesto plebeyo que alcanza la estilización aristocrática y que no desmerecería del de Ambrosio Espínola en Las Lanzas. Se halla también en la lentitud litúrgica del fandango -antípoda de la briosa pero bárbara jota- y en alguna suerte decisiva del toreo, cuando el torero erguido e inmóvil como un ídolo, deja que roce su costado la muerte.

¡Escribir con garbo! Ese será uno de los ideales orteguianos, su modo de ser aristócrata en la plazuela. El señorío idiomático del vocabulario, la frase proverbial, la metáfora, la alusión, la sonoridad, al servicio de la dialéctica de la cosa, todo plasma en párrafo de ritmo lento, donde el decir se va haciendo diáfano y digno a la vez. Se camina "sin prisa y sin pausa, como la estrella", según él mismo ha dicho. Y sería inútil buscar el secreto en las frases aisladas. Está en su enlace, en la composición. La frase normal de Ortega oscila 
entre el octosílabo y el decasílabo y es un arco ascendente-descendente. Pero se combina con otras más largas, explayadas, que suelen ir de las doce a las dieciséis sílabas y aun más lejos, y se alterna con pies quebrados de frase corta, mordiente. El ritmo mirado aisladamente, en el plano de la sonoridad, no aclara gran cosa, pues. Pero si se le considera trascendiendo al ritmo conforme al cual van siendo dichas y sugeridas las ideas, ya es distinto. La frase aseverativa se enlaza con toda normalidad a la exclamación, la interrogación o la duda porque la dialéctica hace brotar la nueva frase al nivel justo a donde había llegado la anterior. Algunas veces ese enlace está trabajado. Notamos que la última palabra de una oración, o la más cargada de sentido, se repite anafóricamente al iniciarse la que sigue. Pero hay muchas frases que no tienen entre sí anáfora expresa y están sólidamente trabadas por un rigor dialéctico fino y perogrullesco juntamente, o sea, garboso. Por lo mismo, el orden lógico-gramatical de cada frase, más que de su índole propia, depende de su enlace con la anterior y de estar prefigurando la siguiente. Es muy libre, en sí mismo, pero funcionalmente es riguroso. Jamás el decir de Ortega resulta apresurado, como lo es tantas veces el barojiano, ni tiene aparentes cambios de velocidad. Tampoco notamos en él esas grandes pausas líricas a que nos invita la puntuación de Azorín. Es que Azorín prepara sus frases montadas al aire como trampolines para el ensueño y la divagación sentimental. En cambio, Ortega las ordena para que sigamos leyendo y le acompañemos hasta un final concreto.

Existe un libro que Ortega publicó sin revisar: Meditación de la Técnica. Si comparamos su estilo con el de los otros, observaremos que hay en él un ritmo más rápido y más desigual. Pues bien, esto basta para que, en algunos momentos, no parezca de Ortega. Hasta tal punto es normal en él su marchar sin prisa y sin pausa, el "despacio y buena letra", que dice la prefilosofía del castellano en una de sus frases acuñadas.

No hay para qué comparar la prosa orteguiana con la de filósofos que no siguen su método. No lo intentaré siquiera. 


\section{COMPLICACIONES DEL ESTILO: LA POLITICA,} EL ORGULLO

En el preámbulo a su diario filosófico, El Espectador, este hombre enamorado del pensar claro, filósofo por vocación, abomina de la política. Mas, a la vez, sabe y proclama que la política es actividad esencial $y$, por añadidura, que la circunstancia española, más que nunca, la exige. El drama del filósofo - su vida - tendrá que aceptar esta contradicción entre el pensar puro y la política y resolverlo como mejor sea posible, echando mano de ese instrumento defectuoso que es la razón humana. He aquí las propias palabras de Ortega:

"La vida española nos obliga, qucramos o no, a la Accrón PoLítica. El inmediato porvenir, tiempo de sociales hervores, nos forzará a ella con mayor violencia. Precisamente por eso yo necesito acotar una parte de mí mismo para la contemplación. Y esto que me acontece, acontece a todos. Desde hace medio siglo, en España y fuera de España, la política -es decir, la supeditación de la teoría a la utilidad- ha invadido por completo el espíritu. La expresión extrema de ello puede hallarse en esa filosofía pragmatista que descubre la esencia de la verdad, de lo teórico por excelencia, en Lo PRÁcтico, en lo titil. De tal suerte, queda reducido el pensamiento a la operación de buscar buenos medios para los fines, sin preocuparse de éstos. He ahí la política: pensar utilitario.

"... La guerra ha sorprendido al europeo sin nociones claras sobre las cuestiones últimas, aquellas que sólo puede aclarar un pensamiento puro e inútil. Nada más natural que, reaccionando contra ese exclusivismo, postulemos ahora, FRENTE A UNA CULTURA DE MEdios UNA CUlTURA DE POSTRIMERías.

“...Mientras tomemos lo útil como útil, nada hay que objetar. Pero si esta preocupación por lo útil llega constituir el hábito central de nuestra personalidad, cuando se trate de buscar la verdadero, tenderemos a confundirlo con lo titil. Y esto, hacer do la utilidad la 
verdad, es la definición de la mentira. El imperio de la politica es, pues, el imperio de la mentira.

Si, congoja de ahogo siento, porque un alma necesita respirar almas afines, $y$ quien ama sobre todo la verdad necesita respirar aire de almas veraces. No he hallado en derredor sino políticos, gentes a quienes no interesa ver el mundo como él es, dispuestos sólo a usar de las cosas como les conviene. Politica se hace en las academias $y$ en las escuelas, en el libro de versos y en el libro de historia, en el gesto rígido del hombre MORAL $y$ en el gesto frívolo del libertino, en el salón de las damas y en la celda del monje. Muy especialmente se hace política en los laboratorios.

"... El Espectador tiene, en consecuencia, una primera intención: elevar un reducto contra la política para mi y para los que compartan mi voluntad de pura visión, de teoría.

"El escritor, para condensar su esfuerzo, necesita de un público, como el licor de la copa en que se vierte. Por esto es El Espectador la conmovida apelación a un público de AMIGOS DE MIRAR, de lectores a quienes interesen las cosas aparte de sus consecuencias, cualesquiera que ellas sean, morales inclusive... Lectores que no exijan ser convencidos, pero, a la vez, se hallen dispuestos a renacer en toda hora de un credo habitual a un credo insólito. Lectores que, como el autor, se hayan reservado un trozo de alma antipolítico. En suma, lectores incapaces de oir un sermón, de apasionarse en un mitin $y$ juzgar de personas y cosas en una tertulia de café.

"...No asevero que la actitud teórica sea la suprema: que debamos primero filosofar, y luego, si hay caso, vivir. Más bien creo lo contrario. Lo único que afirmo es que sobre la vida espontánea debe abrir, de cuando en cuando, su clara pupila la teoría, y que entonces, al hacer teoría ha de hacerse con toda pureza, con toda tragedia. El mal -dice Platón- viené a las repúblicas de que No HACE CADA cUal lo sUYo".

El hombre que escribía esto en 1916 no pudo aislarse, ni a veces quiso, de la política. Eso sí, creyó habitualmente que sólo ejercitaba su afán teórico. Cuando se le hizo obvio que la monarquía tradicio- 
nal ya no era viable en España, lo dijo en un artículo célebre: Delenda est monarchia. ¿Era esto la especulación pura de un filósofo de la historia? Concedámoslo. ¿Dejó de tener consecuencias políticas? Es claro que las tuvo, y muy grandes. Implantada la república, en el momento en que sus enemigos, poderosos pero desorganizados, necesitaban desacreditar aquel régimen, Ortega declaró que la república era "agria y triste”. ¿Tuvo esto consecuencias? También.

Ortega vino a convertirse, queriéndolo o no, en pieza importantísima del juego político español. Contar con él, dado su prestigio, era una ventaja deseable. Los bandos lo cortejaban. Y no simplemente para exhibirlo como afiliado sino con el afán de que fuera la eminencia pública o al menos la eminencia gris que guiara hacia el éxito, pues que él veía claro y con anticipación. Ortega, al no aceptar de plano, defraudó a todos, a unos tras otros.

No hace falta detallar aquí la peripecia política de Ortega. Pero me interesa dejar dicho que la tuvo y la ha tenido hasta el instante de su muerte. $\mathrm{Y}$ es que todo se vuelve política en determinadas circunstancias, como él había pronosticado. Lo es permanecer en España, iniciada la guerra civil, pero también -inexorablemente- el marcharse. Lo es firmar manifiestos e igualmente negarse a firmarlos. Pasados unos años, no regresar a la patria era política y asimismo, aunque de otro tipo, volver a ella. Y después, estar en España, cooperando con el régimen del generalísimo Franco ha sido una política, mientras no cooperar ha constituído, a todas luces, otra diferente.

No puede negarse que la actividad política de Ortega, sobre todo a partir de 1936, ha consistido normalmente en abstenciones. Ha sido la circunstancia la que ha convertido en actos ese afán por mantenerse al margen, como "espectador". Una conducta que recuerda la de Erasmo, un poco la de Montaigne. Y me viene ahora a la memoria que hace tiempo se discutió entre los penalistas españoles si había, además de los delitos por acción y las simples culpas por omisión, otros delitos de comisión por omisión. Pues bien, no hay duda de una cosa: desde la guerra civil en España y, en el mundo, desde que 
empezó la lucha entre democracia y totalitarismo, cuantas omisiones lleva a cabo un sujeto, sea por lo que sea, se encarga la circunstancia de convertirlas en acciones políticas de comisión por omisión. ¡Tan cargado y receloso se halla el ambiente!

Ahora bien, señalado el hecho de la politización que padecemos, puede hacerse honradamente una afirmación: los actos y las omisiones de Ortega señalan en general hacia la defensa del espíritu individual frente al estado. $\mathrm{Y}$ con su drama personalísimo, o sea, perdiendo puestos oficiales, exilándose a veces, fundando institutos culturales privados, muriendo pobre, ha sido un "engagé" o un "mártir de la verdad", de su verdad, que fué esa de querer ser filósofo y hacer lo suyo.

Verdad menor, pero también evidente, es que Ortega se vió complicado y se complicó en algo más que la política española. Ya él dijo, en el texto de El Espectador antes copiado, que hay política en las academias, en las escuelas y, desde luego, en los laboratorios. Pues bien, no olvidemos que Ortega, filósofo original y siempre alerta a las novedades, filósofo para quien el ver claro consistía muchas veces en anticiparse y llamar la atención sobre hechos o teorías incipientes, ha tenido que polemizar sobre su originalidad. En el terreno de la filosofía, no fué una vez ni dos las que vino a hallarse con la política. En cada ocasión que advierte: "esto, que dice ahora en Alemania, o en Inglaterra Fulano de Tal, ya lo había dicho yo en tal fecha", no cabe duda, Ortega hace política de escuela. Responde a la política de otros, que le silencian, que ignoran la "escuela de Madrid".

¿Cómo influyen las intromisiones de lo práctico en el modo de escribir orteguiano? De muchos modos, en verdad.

Cuando reivindica su originalidad lo hace con plena consciencia, en digresiones vivas, que no perjudican su estilo. Es típicamente suyo que no desciende a detalles ni se hace profuso-altura, señorío. Elige la forma intencionada y breve. A veces, hace una concesión: que le cabe cierta responsabilidad por pereza, por no recoger pronto en libros cuanto tiene anticipado en los periódicos. Podríamos 
indagar hasta dónde tal pereza es un tópico literario para suavizar cortésmente el debate. Pero es una cuestión de detalle que aquí sólo dejo insinuada.

Veamos otro caso, algo a que ya me he referido desde otro ángulo al decir que Ortega suele partir de lo obvio y se complace entonces en un razonar aparentemente perogrullesco. Pertenece este método a su dialéctica de la cosa. Así quedó analizado. Mas ahora podemos comprender que es parte, también, de su politica del espiritu, de su lucha contra esa inercia mental que él resume en tres formas degradadas del pensamiento: el sermón, el mitin y la charla de café. La política del espíritu se expresa en clisés orteguianos que están acuñados y son fácilmente recognoscibles: "yo no tengo la culpa de que esto sea así", "es un verdadero escándalo que nadie haya reparado nunca en tal cosa”, etc. El ver claro va, pues, algo más lejos de lo exigido por la dialéctica: se explaya en el júbilo por deshacer rutinas, prejuicios, lugares comunes, ideas fósiles. Si juzgamos todo esto desde el punto de vista literario, debemos distinguir, creo yo, entre el acertado uso de los clisés dentro de un texto determinado y el amaneramiento que resulta de acudir, a lo largo de su obra entera, a formas muy parecidas. Hay quien habla de "orgullo orteguiano" al referirse a estas expresiones. Para mí, son más bien manierismo pedagógico.

Pero el gran choque entre teoría y práctica está, para Ortega, en la cuestión de para quién se escribe. Siempre le desazonó a nuestro filósofo, muy alerta a que escribir es un diálogo, precisamente por sus meditaciones sobre la índole del lenguaje. Ortega quisiera escribir para las "almas afines" de que hace mención en el prefacio de El Espectador. Con todo, acaso lo van a leer otras gentes, broncas, rebeldes, y ante tal posibilidad, el alma de Ortega se debate en la contradicción: desea y teme a la vez que ello ocurra. En verdad, escribir únicamente para las minorías sería sencillo. El problema está en que se escribe para todo el mundo, también para las masas. ¡Ojalá que las masas lean y entiendan! Dejarían de serlo. Pero es de temer, fundadamente, que tergiversarán lo leído. 
En variọs de sus libros, especialmente en La rebelión de las masas, nos ha dicho Ortega lo que piensa sobre minoría y masa. Es minoritario, psicológicamente, el hombre capaz de asombro. "Sorprenderse, extrañarse, es comenzar a entender”. Lo es, sociológicamente, el capaz de crear, o sea, de dar una respuesta auténtica al problema vigente. $\mathrm{Y}$ ambas cosas emanan de valores vitales máximos: exigirse más de lo que se exigen los otros, sentirse distinto de ellos, tener un exceso de vitalidad, en suma. En cambio, el hombremasa está satisfecho de su inercia y de su medianía. "Como se dice en Norteamérica, ser diferente es indecente".

"La división de la sociedad en masas y minorías excelentes no es, por tanto, una división en clases sociales sino en clases de hombres... En rigor, dentro de cada clase social, hay masa y minoría auténtica... Así, en la vida intelectual, que por su misma esencia requiere y supone la cualificación, se advierte el progresivo triunfo de los seudointelectuales incualificados, incalificables y descalificados por su propia contextura. Lo mismo en los grupos supervivientes de la "nobleza" masculina y femenina. En cambio, no es raro encontrar hoy entre los obreros, que antes podían valer como el ejemplo más puro de esto que llamamos "masa", lalmas egregiamente disciplinadas".

Un caso concreto será el de la masa leyendo a su manera. Esto a Ortega le preocupa, hasta le indigna:

"Tal vez padezco un error; pero el escritor, al tomar la pluma para escribir sobre un tema que ha estudiado largamente, debe pensar que el lector medio, que nunca se ha ocupado del asunto, si le lee, no es con el fin de aprender algo de él sino, al revés, para sentenciar sobre él cuando no coincide con las vulgaridades que este lector tiene on la cabeza".

En definitiva, el filósofo se enreda en su tragedia vital, hasta pierde la claridad de visión. No se limitó a su cátedra y a sus libros. Filosofó en diarios de España y América, salió a la plazuela del periodismo. ¿No fué esto humildad, cariño hacia la gente distraída y pobre, que es masa pero no tiene la culpa de serlo? Pues bien, hay 
quien se lo reprocha. Y él mismo se lo reprocha en ocasiones. Porque el hecho indignante, en una España tan "invertebrada" como la que él contempla, es que hay duquesas-masa - la mayoría-, coroneles y generales-masa, magistrados, financieros, profesores de filosofía, obispos que son masa y no debieran serlo. $Y$ si es grato constatar que ya existen algunos obreros egregios, exigentes consigo mismo, es tristísimo constatar la presencia de tanto belitre, encastillado en su rancia inopia y que se toma por aristócrata y selecto. ¡Qué gran triunfo sería salvar a algunas de estas gentes de su estupidez! ¡Sí, pero qué arriesgado!

Ahora bien, las transiciones - en cuanto a suponer quién le está leyendo: almas afines, masa ingenua, masa pseudo selecta- son en Ortega rápidas, hasta inesperadas. Y entonces, por fin, es cuando aparece en él su orgullo, en forma de burla agresiva, de imprecación, de trallazo. Páginas atrás, he negado yo que expresaran orgullo ciertos rasgos del estilo orteguiano. En cambio, es evidente que lo hay al dirigirse al falsificador de la cultura, o sea, al intelectual-masa, a a todos los que se toman por minoría y carecen de espíritu creador. Ortega es con ellos agresivo como un profeta si es menester, pero se conforma en general con desdeñarles. Tal actitud, que aflora en él como en cualquier hombre limpio, si indigna a los afectados más es por lo certero de la puntería. Nadie, por ejemplo, llama orgulloso a Antonio Maçhado. Sin embargo, ¿quién escribió aquellos versos donde se dice?:

Y en suma, nada os debo, debéisme cuanto he escrito...

El orgullo de Ortega, que es dignidad frente al orgullo sin causa, es, pues, una reacción normal en todo gran espíritu. Lo interesante, para mi propósito, es observar que cuaja en frases estupendas, de una gran variedad en el estilo. Hay casos de evasión fina, como aquella fantástica apelación al lector del año 2000, que en otro sitio he comentado. Ortega perdona el golpe directo al lector-masa. Se limita a herirle oblicuamente, poniéndole a un lector hipotético y digno en 
parangón. Otras veces la burla es más directa y está hecha con garbo andaluz del mejor:

¿Qué son los políticos afiliados a cste o el otro partido?

"Por lo pronto no son nunca los que pensaron originariamente la idea en torno a la cual se formó el partido... No son, pues, gentes que hayan, por si mismas, pensado nunca en nada. Se han encontrado con un partido hecho que pasaba delante de ellos y lo han tomado como se toma un autobús" (ОвRAs Completas, IV, 75).

La vulgaridad del ejemplo metafórico y, dentro de él, lo voluminoso del autobús, que forma su núcleo sonoro y significativo, expresan muy bien lo gordo del error que está cometiendo el tal político, al tenerse por hombre valioso.

Por supuesto, hay casos más duros aún: aquellos en que Ortega se defiende primero y después contraataca. Un buen ejemplo, en La rebelión de las masas, me parece éste:

"Vivimos bajo el brutal imperio de las masas. Perfectamente; ya hemos llamado dos veces brutal a este imperio, ya hemos pagado nuestro tributo al dios de los tópicos; ahora, con el billete cn la mano, podemos alegremente ingresar en el tema, ver por dentro el espectáculo. ¿O se creía que iba a contentarme con esa descripción, tal vez exacta, pero externa?... Si yo dejase aquí cste asunto y estrangulase sin más mi presente ensayo, quedaría el lector pensando, muy justamente, que este fabuloso advenimiento de las masas a la superficie de la historia no me inspiraba otra cosa que algunas palabras displicentes, desdeñosas, un poco de abominación y otro poco de repugnancia; a mi, de quien es notorio que sustento una interpretación de la historia radicalmentc aristocrática... Nadie puede creer que, frente a este fabuloso encrespamiento de la masa, sea lo aristocrático contentarse con hacer un breve mohín amanerado, como un caballerito de Versalles. Versalles - se entiende ese Versalles de los mohines- no es aristocracia, es todo lo contrario: es la muerte y la putrefacción de una magnifica aristocracia... No, a quien sienta la misión profunda de las aristocracias, el espectáculo de la masa le incita y enardece como al escultor la presencia del mármol virgen. 
La aristocracia social no se parece nada a ese grupo reducidisimo que pretende asumir para si integro el nombre de "sociedad", que sc llama a si mismo "la sociedad" y que vive simplemente de invitarse o de no invitarse".

Lo lamentable, desde nuestro punto de vista, es que algunas veces la invectiva se embosca sin desarrollarse, y forma síntesis confusas con otros puntos de vista, conduciendo al error. Como en el final de aquel trozo, ya citado:

"Dócil a la circunstancia, he hecho que mi obra brote en la plazuela intelectual que es el periódico. No es necesario decir que se me ha censurado constantemente por cllo. Pcro algún acierto debía haber en tal resolución cuando de esos artículos de periódico han hecho libros formales las imprentas extranjeras".

Es una desmesura afirmar de sí mismo que sólo ha escrito artículos. Desde un principio, y en España, Ortega publicó libros. Veamos qué fuerzas han conformado el párrafo. Un viejo motivo de apóstrofe patriótico - el "nadie es profeta en su tierra"- está fundido aquí con una alusión retorcida a los editores fraudulentos. Sí, el editor que allá, en el extranjero, lo edita y no le paga sus derechos, lo burla como propietario pero lo estima - y acaso lo entiende- como valor intelectual. Estas ideas son las que han enturbiado, hasta falsearla, la verdad principal: que él, Ortega, no se encerró en la cómoda torre de marfil, que aceptó su destino y se comprometió.

Por lo demás, Ortega sabe muy bien qué es el orgullo. Lo ha analizado magistralmente en su ensayo: Para una topografía de la soberbia española. Es una actitud valorativa del hombre en ciertos casos:

"La contradicción entre lo que él cree verdadera relación jerárquica y la que ve afirmada por los otros es tal, que si aceptase ésta scría como aceptar la propia antlación".

Entonces el orgulloso se yergue, hasta físicamente, para afirmarse, exhibe su “altanería”. Pero ¡cuidado! nos dice Ortega, si la protesta del individuo es fundada, el orgullo es normal:

"Será más bien la natural indignación provocada por la ceguera 
de otro u otros que se obstinan en subvertir una jerarquía cvidentc".

La soberbia anómala e intolerable es la "suficiencia", el bastarse a sí mismo por ignorar lo ajeno. Se da en almas sin porosidad, sin capacidad de asombro. Y a veces, como el pseudo aristócrata español, no se basa en creerse el más inteligente, el más justo, el más sensible al arte -en poseer valores máximos- sino en el valor elemental y mínimo de "ser hombre". Contra este orgullo patológico reacciona la "natural indignación” del filósofo.

Enero de 1956. 